\title{
Intimin from enteropathogenic Escherichia coli mediates remodelling of the eukaryotic cell surface
}

\author{
Alan D. Phillips, ${ }^{1}$ Jorgé Giròn, ${ }^{2}$ Susan Hicks, ${ }^{1}$ Gordon Dougan ${ }^{3}$ \\ and Gad Frankel ${ }^{3}$ \\ Author for correspondence: Alan D. Phillips. Tel: +44 207830 2783. Fax: +44 2078302146. \\ e-mail: adphill@rfhsm.ac.uk
}

1 University Department of Paediatric

Gastroenterology, Royal Free Hospital, London NW3 2QG, UK

2 Centro de Investigaciones Microbiológicas, Benemérita Universidad Autónoma de Puebla, Puebla, México

3 Department of Biochemistry, Imperial College of Science, Technology and Medicine, London SW7 2AZ, UK
Adhesion to cultured epithelial cells by enteropathogenic Escherichia coli (EPEC) is associated with extensive rearrangement of the host cell cytoskeleton. Evidence has been presented that EPEC adhesion is associated with activation of signal transduction pathways leading to production of a characteristic histopathological feature known as the attaching and effacing (A/E) lesion. A/E lesion formation requires intimin, an EPEC adhesion molecule and several EPEC secreted proteins (EspA, B, D and Tir) involved in cell signalling and protein translocation. In this study it is shown that HEp-2 cells respond during the early stages of infection with two wild-type EPEC strains (B171 and E2348/69) by producing microvillus-like processes (MLP) at the site of initial bacterial adherence. Intimin appears to play a key role in MLP elongation. At later stages of infection with these wild-type EPEC strains, when A/E lesions have formed, the MLP were reduced in number and length to appear as at time zero, and the cell surface in the vicinity of bacterial clusters appeared unaffected. In contrast, infection with EspA- or EspB-negative, but intimin-positive, EPEC strains (UMD872 and UMD864, respectively) resulted in enhanced MLP proliferation and formation of 'cage-like' structures engulfing the bacteria. Inoculating HEp-2 cells with intimin-coated latex spheres induced similar 'cage-like' structures. Caco-2 cells did not show intimin-induced microvillus elongation in response to EPEC infection, although microvillus effacement and reduction in number occurred. Similar phenomena appeared on B171 and E2348/69 infection of paediatric intestine using in vitro organ culture, i.e. elongated microvilli were seen in association with small colonies and at the periphery of large localized colonies, along with evidence of microvillus breakdown and debris in the colony centre. These results show that intimin activates signal transduction pathways involved in the remodelling of the eukaryotic cell surface, probably via binding to a receptor encoded by the host cell.

Keywords: enteropathogenic Escherichia coli, intimin, cell culture, in vitro organ culture, microvilli

\section{INTRODUCTION}

Diarrhoeal diseases are amongst the leading causes of

Abbreviations: $A / E$, attaching and effacing; $B f p$, bundle-forming pilus; EAF, EPEC adherence factor; EPEC, enteropathogenic Escherichia coli; Esp, EPEC secreted protein; IVOC, in vitro organ culture; LA, localized adherence; LEE, locus of enterocyte effacement; MLP, microvillus-like processes; SEM, scanning electron microscopy; Tir, translocated intimin receptor. early childhood mortality in the developing world. A common aetiological agent of severe diarrhoea in infants is enteropathogenic Escherichia coli (EPEC) (Nataro \& Kaper, 1998). Infection with EPEC is associated with a microscopic lesion of intestinal epithelial cells, the attaching and effacing (A/E) lesion (Moon et al., 1983), which is characterized by destruction of host cell microvilli and intimate attachment of bacteria to cuplike pedestals at the apical cell membrane (Ulshen \& 
Rollo, 1980). Infection of cultured epithelial cells by EPEC not only induces A/E lesions (Knutton et al., 1987a), but also produces a characteristic pattern of adherence, termed localized adherence (LA) (Scaletsky et al., 1984), similar to that seen in human intestinal biopsies, both in vivo (Rothbaum et al., 1983) and in vitro (Hicks et al., 1998; Knutton et al., 1987b). The LA phenotype is associated with the presence of a 50$60 \mathrm{MDa}$ EPEC adherence factor (EAF) plasmid (Baldini et al., 1983), which encodes a type 4 pilus termed bundleforming pilus (Bfp) (Giron et al., 1991) and a transcriptional activation factor called Per (Gomez-Duarte \& Kaper, 1995).

Several genes have been implicated in $\mathrm{A} / \mathrm{E}$ lesion formation - all of these map to a pathogenicity island termed the locus of enterocyte effacement or the 'LEE' region (McDaniel et al., 1995). The LEE region encodes a type III secretion system (Jarvis et al., 1995), with four associated EPEC secreted proteins [EspA, EspB, EspD and a translocated intimin receptor (Tir); Kenny et al., 1997; Lai et al., 1997; Donnenberg et al., 1993; Kenny et al., 1996; respectively], and an outer-membrane adhesin, intimin (Jerse et al., 1990). Recently, several significant discoveries concerning EPEC pathogenesis have been reported (reviewed by Frankel et al., 1998). Kenny et al. (1997) showed that Tir is in fact an EPEC secreted protein which is encoded by the LEE region and translocated into the host cell from where it is incorporated into the surface membrane of infected host cells, whilst Knutton et al. (1998) described a surface EPEC organelle, made predominantly from one of the EPEC secreted proteins, EspA, which not only bridges between EPEC and the target host cells but is also required for translocation of proteins, including EspB (Knutton et al., 1998; Wolff et al., 1998) and Tir (Kenny et al., 1997).

The signal(s) and the mechanisms responsible for EPECinduced cytoskeletal reorganization are currently unknown although Rac-, Rho- and Cdc42-dependent pathways and stimulation of the classical phospholipase $\mathrm{C}$ pathway leading to production of IP3 and release of calcium from IP3-sensitive intracellular stores do not appear to be involved (Bain et al., 1998; Ben-Ami et al., 1998). Recent studies have highlighted the possible recruitment and activation of host cell factors involved in actin polymerization, i.e. Wiskott-Aldrich syndrome proteins (WASP) and the Arp2/3 complex, in EPECinduced pedestal formation (Kalman et al., 1999). In addition, several other signal transduction pathways appear to be stimulated in epithelial cells following infection with EPEC, including phosphorylation of translocated Tir (Kenny et al., 1997), intimin-dependent tyrosine phosphorylation of phospholipase C- $\gamma 1$ (Kenny \& Finlay, 1995), tyrosine phosphorylation of several other host cell proteins (Rosenshine et al., 1992; Rosenshine \& Finlay, 1993), serine/threonine phosphorylation of myosin light chain (ManjarrezHernandez et al., 1996) and dephosphorylation of a $240 \mathrm{kDa}$ host cell protein (Kenny \& Finlay, 1997).

The first gene to be associated with A/E activity was the eae gene encoding the intimate EPEC adhesin, intimin (Jerse et al., 1990). We have established that there are four different intimin types $(\alpha, \beta, \gamma$ and $\delta)$ using serological and molecular approaches (Adu-Bobie et al., 1998). For intimin to mediate adherence to eukaryotic cells it must bind to a cell-surface receptor(s), and studying the intimin family of proteins, we showed that their cell-binding activity is localized to the C-terminal 280 amino acids (Int280) (Frankel et al., 1994), that purified Int 280 can bind to HEp-2 cells on its own (Frankel et al., 1995, 1996b), that a specific cysteine residue in EPEC intimin (Cys937) is essential for binding activity (Hicks et al., 1998; Frankel et al., 1995), that intimin is required for colonization of the mucosa and $\mathrm{A} / \mathrm{E}$ lesion formation in a human intestinal organ culture model of infection (Hicks et al., 1998), and that Int280 can bind to $\beta 1$-integrins (Frankel et al., 1996a).

Recently, the global fold of Int 280 in solution was determined by multidimensional NMR (Kelly et al., 1999). The structure shows that Int280 is approximately $90 \AA$ in length and built from three globular domains: domain 1 (residues 1-91), domain 2 (residues 93-181) and domain 3 (residues (183-280). The first two domains resemble the type I set of the immunoglobulin super family (IgSF). The IgSF domains in intimin form an articulated linker that most likely extends away from the bacterial surface and confers a highly accessible third domain (D3) for potential interaction. Despite a lack of significant sequence homology, the topology in Int280-D3 is reminiscent of the C-type lectins, a family of proteins responsible for cell-surface carbohydrate recognition. Modelling other intimin types (including the enterohaemorrhagic E. coli intimin $\gamma$ derivative) revealed similar structures which define a new family of bacterial adhesion molecules (Kelly et al., 1999). We also reported that both Int 280 and Int $280 \mathrm{C} / \mathrm{S}$ or Int280C/A (biologically inactive forms of Int280 in which Cys937 has been substituted with Ser or Ala, respectively) bind Tir and that Int 280 but not Int $280 \mathrm{C} / \mathrm{S}$ binds to cells in the absence of Tir (Hartland et al., 1999). Together, these data provide strong evidence that intimin interacts not only with Tir but also with a host cell intimin receptor.

The present study, performed on two different prototype EPEC strains (B171 and E2348/69) expressing intimin $\beta$ and $\alpha$, respectively, shows that EPEC induce transient proliferation and elongation of microvillus-like processes (MLP) on the eukaryotic cell surface. These structures appeared to enmesh and anchor bacteria to the cell surface. Elongation of microvilli around sites of A/E lesion formation has been described on infection of human intestine in vitro (Hicks et al., 1998; Knutton et al., 1987b), and this prompted further investigation of the phenomenon using in vitro cell culture of Caco-2 cells and organ culture of paediatric intestine. Further evidence is provided to show that intimin can bind to 'non-activated' HEp-2 cells: (a) proliferation and elongation of MLP were evident on HEp-2 cells inoculated with Int280-coated plastic beads, and (b) HEp-2 cells responded to infection with UMD864 (intimin- 
positive, EspB-negative) by increasing the MLP network during early stages; later this developed into 'cage-like' structures surrounding the bacteria. These results show that MLP production is an intimin-dependent event and that intimin can induce significant cytoskeletal reorganization, but not $\mathrm{A} / \mathrm{E}$ lesion formation, in the absence of Esp-dependent signal transduction and intimin-Tir interaction.

\section{METHODS}

Bacterial strains. The bacterial strains and plasmids used in this study are listed in Table 1 . Bacteria were routinely grown overnight statically in Luria broth at $37^{\circ} \mathrm{C}$.

Adherence assays - HEp-2 and Caco-2 cells. Adherence of EPEC to epithelial cells was studied using cultures of HEp-2 cells grown on glass coverslips (Cravioto et al., 1979). An inoculum of $1 \times 10^{6}$ c.f.u. $\mathrm{ml}^{-1}$ was incubated with a monolayer of the cultured cells grown in Dulbecco's modified Eagle's medium $(0 \cdot 1 \%$ glucose $)$ containing $10 \%$ foetal calf serum, $10 \mathrm{mM}$ L-glutamine (complete medium) and $0.5 \% \mathrm{D}-$ mannose at $37{ }^{\circ} \mathrm{C}$ with $5 \% \mathrm{CO}_{2}$. At different time points postinfection, the infected cultures were washed five times with PBS (0.01 M phosphate buffer, 0.0027 M potassium chloride, $0 \cdot 137 \mathrm{M}$ sodium chloride, $\mathrm{pH} 7 \cdot 4$ ), fixed and prepared for scanning electron microscopy (SEM). Caco-2 cells were cultured in a similar fashion except that a higher glucose concentration $(0.45 \%)$ was used, and cells were grown for $10 \mathrm{~d}$ prior to use, to ensure they were confluent and polarized.

Construction and purification of MBP-Int fusion proteins, coating of Covaspheres, HEp-2 adherence assay and actin staining. MBP-Int280 and MBP-Int280C/S (MBP-Int280 in which Cys937 was replaced with Ser) fusion proteins were constructed, expressed and purified as previously described (Frankel et al., 1994, 1995). Polymer micro-spheres (Covaspheres MX; Duke Scientific) were coated with MBPInt280 and MBP-Int280C/S fusion proteins according to the manufacturer's instructions. For cell-binding assays, $10 \mu \mathrm{l}$ of the coated Covasphere suspension were added to subconfluent HEp-2 cells in complete medium and the monolayers were incubated for $3 \mathrm{~h}$ before washing three times with PBS. Adherence of beads to the cells was visualized by SEM (Frankel et al., 1996b). Fluorescent actin staining was performed as described by Knutton et al. (1989).

Paediatric intestinal in vitro organ culture (IVOC). This was performed as described previously (Hicks et al., 1998). The experiments were maintained for $8 \mathrm{~h}$ with a change of tissue culture medium every $2 \mathrm{~h}$ and an uninoculated specimen was included with each experimental culture to act as a negative control. Tissue was obtained with fully informed parental consent and ethical approval. All intestinal histology was reported to be normal.

Strains B171 and E2348/69 were each examined in IVOC on three occasions using tissue from different children. The distal duodenum (two male, one female; aged 40, 109 and 120 months) and terminal ileum (one male aged 87 months) was sampled using grasp biopsy forceps during routine endoscopic (Olympus PCF paediatric endoscope) investigation of intestinal disorders. Endoscopically normal ileal resection margin was sampled from two children undergoing formation of an ileostomy (one male aged 190 months and one female aged 172 months). CVD206 (intimin-minus) and UMD864 (EspBminus) were incubated in IVOC with one duodenal (male aged 24 months) and four ileal (males aged 48, 172 and 190 months, and one female aged 173 months) samples; E2348/69 was used as a positive control in four cases and B171 in one (ileum; aged 172 months). In addition, in two of the cases (males aged 24 and 190 months) CVD206 and UMD864 were co-incubated for the $8 \mathrm{~h}$ period. After the culture period specimens were washed thoroughly three times to remove any non-adherent bacteria and then prepared for SEM as described below.

SEM. After the adherence assay, samples were fixed with $2.5 \%$ glutaraldehyde in $0 \cdot 1 \mathrm{M}$ sodium phosphate buffer, post-fixed in $1 \%$ aqueous osmium tetroxide and dehydrated in 2,2dimethoxypropane. Specimens were transferred to absolute ethanol, critical-point-dried using liquid carbon dioxide in an Emitech K850 apparatus, coated with gold-palladium using a Polaron E5100 sputter coater, and viewed at $30 \mathrm{kV}$ in a JEOL 5300 scanning electron microscope.

\section{RESULTS}

\section{EPEC induces elongation and polarization of cellular MLP on HEp-2 surfaces}

In this study the surface of infected HEp-2 cells was examined at several time points post-infection with two different prototype EPEC strains, B171 (O111:NM) and E2384/69 (O127:H6), and with E2348/69 derivatives using SEM. Adhesion of EPEC strain B171 (expressing intimin $\beta$ ) to HEp-2 cells stimulated MLP to increase in number and length (to over $15 \mu \mathrm{m}$ long) and to polarize towards the growing bacterial clusters (MLP elongation) (Fig. 1). Chronologically, when bacteria first appeared

Table 1. Bacterial strains and plasmids

\begin{tabular}{|lll|}
\hline Strain/plasmid & \multicolumn{1}{c|}{ Description } & \multicolumn{1}{c|}{ Reference } \\
\hline B171 & Wild-type $\left(\mathrm{O} 111: \mathrm{H}^{-}\right)$, expressing intimin $\beta$ & Giron et al. $(1991)$ \\
E2348/69 & Wild-type $(\mathrm{O} 127: \mathrm{H} 6)$, expressing intimin $\alpha$ & Levine et al. $(1978)$ \\
JPN15 & EAF-plasmid-cured derivative of E2348/69 & Jerse et al. $(1990)$ \\
CVD206 & An eae-deficient derivative of E2348/69 & Donnenberg \& Kaper (1991) \\
UMD864 & An espB-deficient derivative of E2348/69 & Donnenberg et al. (1993) \\
UMD872 & An espA-deficient derivative of E2348/69 & Kenny et al. (1996) \\
pMSD3 & Cloned espB & Donnenberg et al. (1993) \\
pCVD450 & Cloned per & Gomez-Duarte \& Kaper (1995) \\
\hline
\end{tabular}



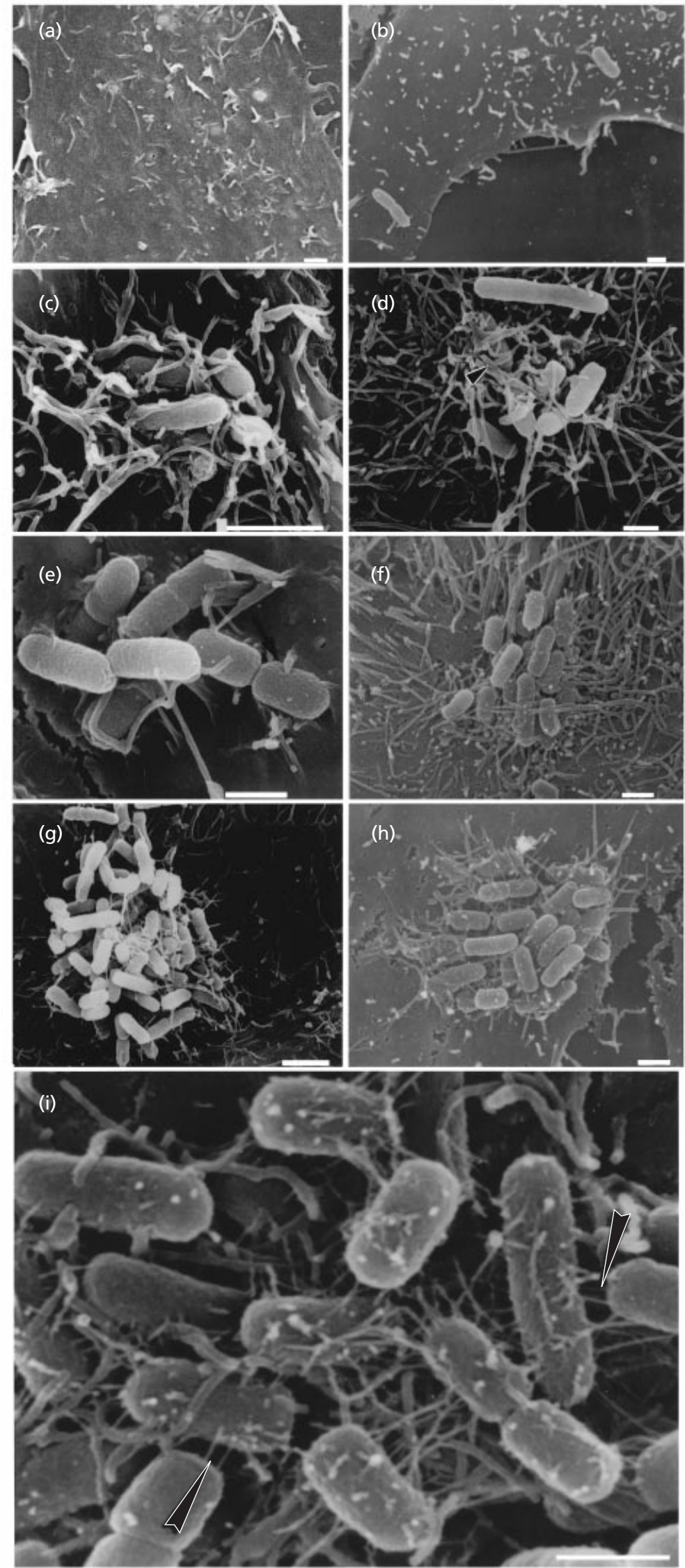

Fig. 1. Scanning electron micrographs showing the kinetics of cellular MLP elongation during HEp-2 cell infection with B171 for 20 (b), 40 (c), 60 (d), 80 (e), 100 (f), 120 (g), 140 (h) and 180 (i) min. Noninfected HEp-2 cells are shown in (a). Note the increase in number and length of MLP in time, as well as the apparent mobilization or polarization of these elongated MLP towards the anchored bacteria. The MLP appear to enmesh bacteria at the cell surface (arrow in d). By 140 min postinfection, the epithelial cell surface surrounding the LA cluster appears normal without obvious elongated MLP. Interbacterial filaments are apparent in (i) which may represent Bfp (arrow). Bars: $1 \mu \mathrm{m}(\mathrm{a}, \mathrm{b}$, $\mathrm{d}, \mathrm{f}-\mathrm{i}) ; 10 \mu \mathrm{m}(\mathrm{c}, \mathrm{e})$. 

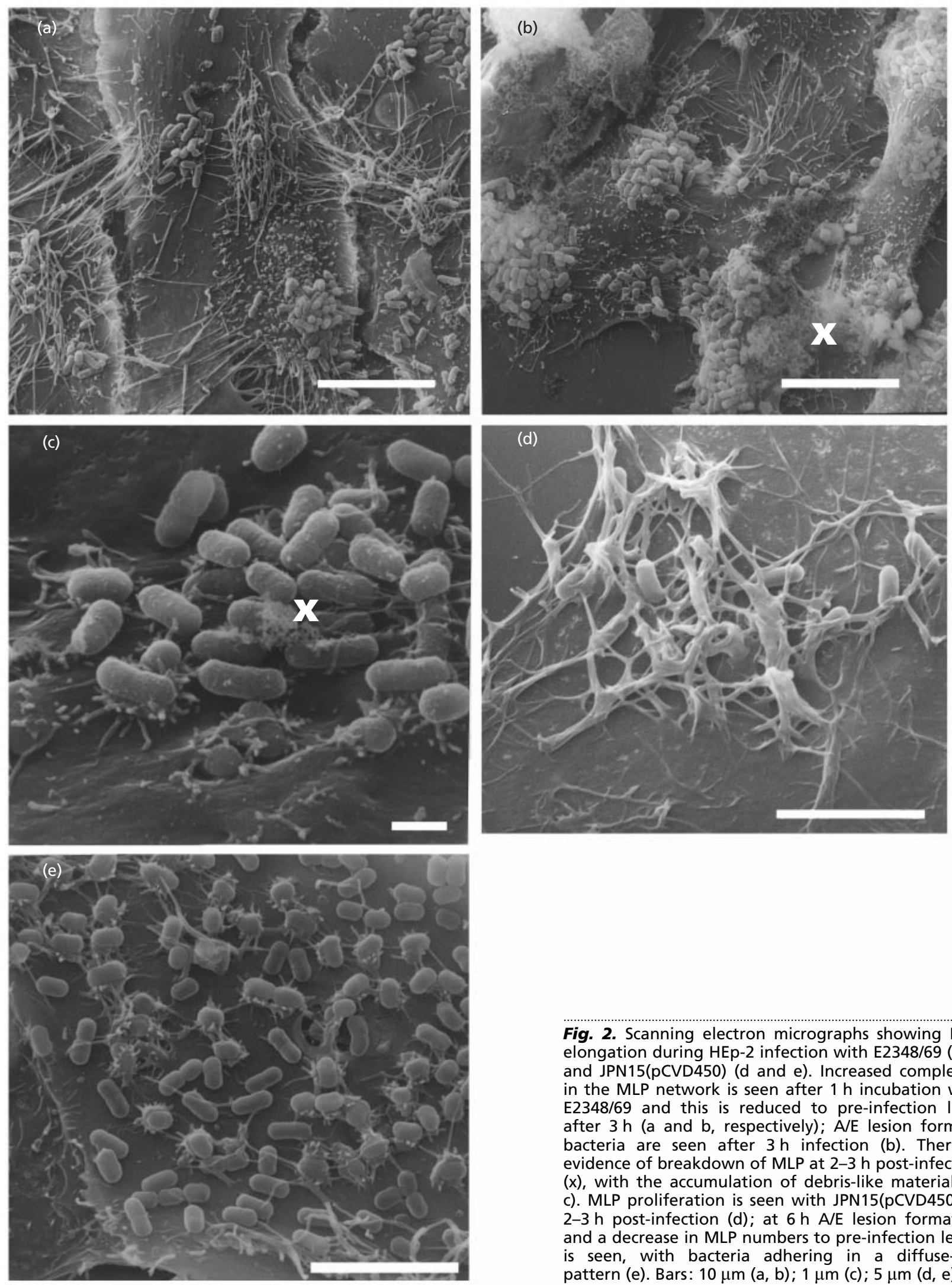

Fig. 2. Scanning electron micrographs showing MLP elongation during HEp-2 infection with E2348/69 (a-c) and JPN15(pCVD450) (d and e). Increased complexity in the MLP network is seen after $1 \mathrm{~h}$ incubation with E2348/69 and this is reduced to pre-infection level after $3 \mathrm{~h}$ ( $a$ and $b$, respectively); A/E lesion forming bacteria are seen after $3 \mathrm{~h}$ infection (b). There is evidence of breakdown of MLP at 2-3 h post-infection $(x)$, with the accumulation of debris-like material (b, c). MLP proliferation is seen with JPN15(pCVD450) at $2-3 \mathrm{~h}$ post-infection (d); at $6 \mathrm{~h}$ A/E lesion formation and a decrease in MLP numbers to pre-infection levels is seen, with bacteria adhering in a diffuse-like pattern (e). Bars: $10 \mu \mathrm{m}(\mathrm{a}, \mathrm{b}) ; 1 \mu \mathrm{m}(\mathrm{c}) ; 5 \mu \mathrm{m}(\mathrm{d}, \mathrm{e})$. 

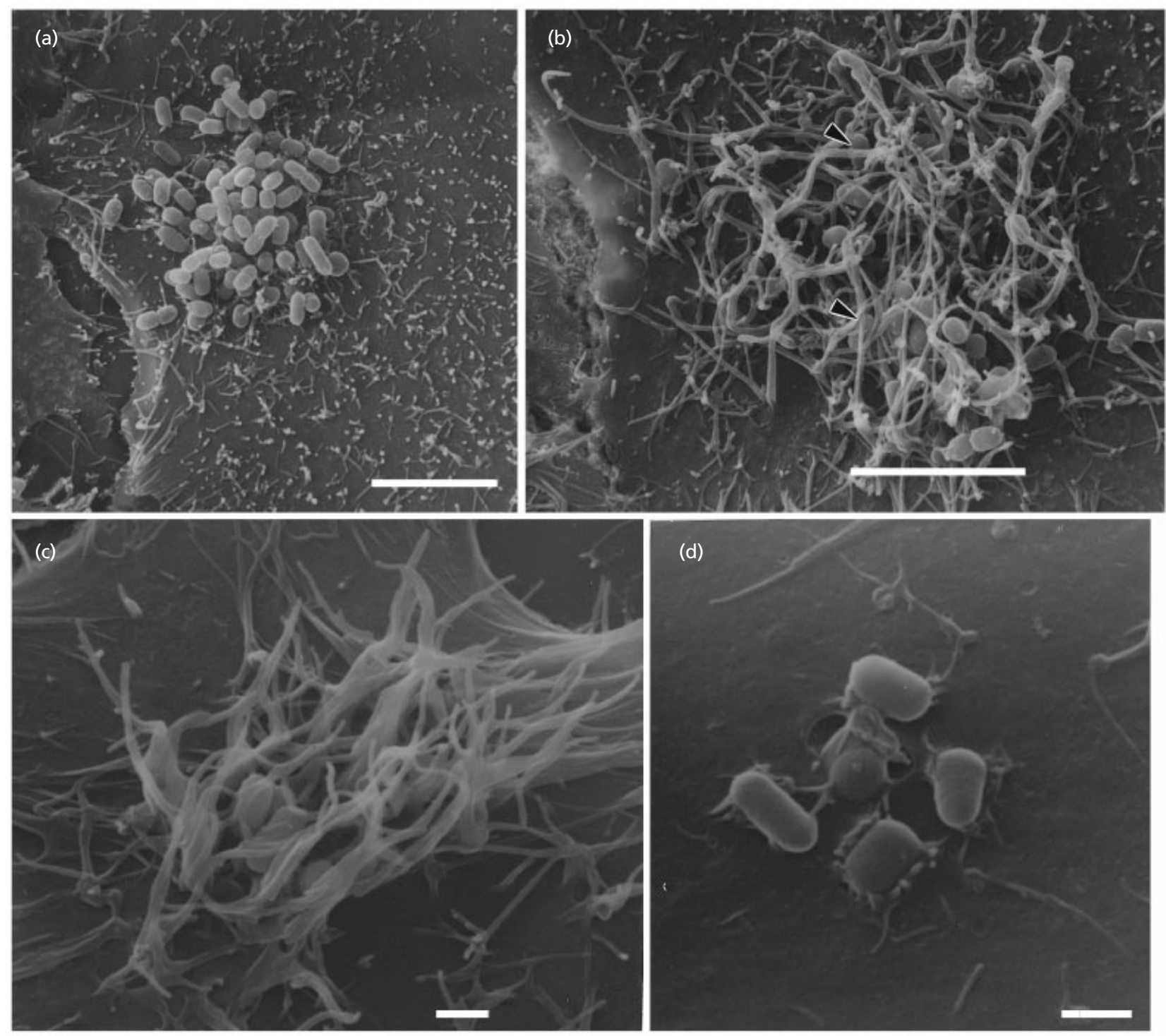

Fig. 3. Scanning electron micrographs showing interaction of HEp-2 cells with E2348/69 derivatives. No MLP elongation is seen after $2 \mathrm{~h}$ infection with CVD206 (a). In contrast, UMD864 induces constitutive MLP elongation that results in increased complexity in the MLP network with time. After $3 \mathrm{~h}$ incubation, bacteria (arrows) are seen trapped within 'cage-like' structures (b); note the length and thickness of individual MLP. After $6 \mathrm{~h}$, few UMD864 are attached to HEp-2 cells, but 'cage-like' structures remain (c). No MLP are seen with the EspB-complemented strain UMD864(pMSD3) at $3 \mathrm{~h}$ when A/E lesion forming bacteria are present (d). Bars: $5 \mu \mathrm{m}(a, b) ; 1 \mu \mathrm{m}(c, d)$.

adhering to the cell surface ( 20 min post-infection), MLP length, polarization and distribution resembled those of non-infected cells (Fig. $1 \mathrm{~b}$ and a, respectively). As the infection proceeded, elongated MLP reached and interacted intimately with the bacteria (Fig. 1e). Around 60 min post-infection, the MLP were several micrometres long and extended some distance to recruit or confine the adhering bacteria. It would seem that the MLP were mobilized and polarized to the areas of higher bacterial density. By 140 min post-infection, most of the elongated MLP were confined to the micro-colonies and the MLP neighbouring the LA cluster were similar in length to those at time zero; the cell surface in the vicinity of the LA cluster appeared unaffected (Fig. 1h).
Similar alteration to MLP were observed during early and late stages of HEp-2 cell infection with EPEC strain E2348/69 (expressing intimin $\alpha$ ) (Fig. 2a and b). In addition, there was evidence of breakdown of MLP at $2-3 \mathrm{~h}$ post-infection with the accumulation of debrislike material in areas around MLP, which were near normal in length (Fig. 2c). No elongated MLP were evident during E2348/69 infection of formaldehydefixed HEp-2 cells or in the presence of cytochalasin D (data not shown). Moreover, the induced HEp-2 MLP were stained positively by FITC-labelled phalloidin, which specifically binds to polymerized micro-filaments (not shown). These results confirm that the elongated MLP are eukaryotic in nature. 
Changes to the surface of HEp-2 cells were also recorded after infection with JPN15(pCVD450), an E2348/69 derivative cured of the EAF plasmid, but harbouring the per locus, which regulates intimin expression (GomezDuarte \& Kaper, 1995; Knutton et al., 1997). These observations revealed that at 1 and $2 \mathrm{~h}$ post-infection, JPN15(pCVD450) induced MLP proliferation, elongation and cage formation (Fig. 2d). However, at $6 \mathrm{~h}$ post-infection, the majority of adherent bacteria produced the A/E lesion whilst the MLP decreased in numbers and returned to their pre-infected level (Fig. 2e); bacteria adhered to the HEp-2 cell surface in a diffuse-like pattern (Fig. 2e), without evidence of complex colony formation as shown by E2348/69 (Fig. 2b).

\section{Elongation of MLP is intimin-mediated}

To study the contribution of individual EPEC virulence factors to the phenomenon of MLP elongation, the interaction of E2348/69 derivatives [strains CVD206 (intimin-minus), UMD864 (EspB-minus) and UMD872 (EspA-minus)] with HEp-2 cells was investigated using SEM (Fig. 3). HEp-2 cells infected with CVD206 for 1 (not shown), 2 (Fig. 3a), 3 or $6 \mathrm{~h}$ (not shown) presented short MLP, similar to control cells, scattered on the cell surface. Small bacterial clusters were seen at $1 \mathrm{~h}$, but larger and more numerous colonies were present at 2 and $3 \mathrm{~h}$. In contrast, strains UMD864 (Fig. 3b) and UMD872 (data not shown) both induced a profound MLP mobilization and polarization to the area of adherent bacteria. This effect was much more enhanced compared with HEp-2 cells infected with E2348/69. Moreover, the complexity of the MLP network increased in time and by $3 \mathrm{~h}$ post-infection the bacteria could be seen trapped within 'cage-like' structures formed by the elongated MLP. These were confined to the area of adherent bacteria (Fig. 3b). The surrounding cellular membrane presented MLP similar to uninfected control cells. After $6 \mathrm{~h}$ incubation, few UMD864 remained attached to HEp-2 cells. Nevertheless, extensive 'cage-like' structures, sometime resembling membrane ruffles, but with few bacteria enmeshed, were present on the cell surface (Fig. 3c). No debris-like material was observed. When espB was reintroduced into UMD864 on a plasmid, to produce strain UMD864(pMSD3), the phenotype returned towards that seen in the wild-type E2348/69, i.e. elongated MLP were present at early time points $(1$ and $2 \mathrm{~h}$, data not shown), and were reduced in presence at 3 and $6 \mathrm{~h}$, particularly at sites of A/E lesion formation (Fig. 3d). UMD864 and UMD872 have been shown to be deficient in transducing Esp-dependent biochemical signals (Kenny et al., 1996; Lai et al., 1997) and translocation of Tir (Kenny et al., 1997), which are required for A/E lesion formation although they still express intimin at a normal level (data not shown). Therefore, these results show that MLP elongation and 'cage formation' is a function dependent upon intimin expression. Supporting this was the finding that incubating HEp-2 cells with Int280-coated, but not Int $280 \mathrm{C} / \mathrm{S}$-coated, Covaspheres resulted in MLP elongation and mesh formation in
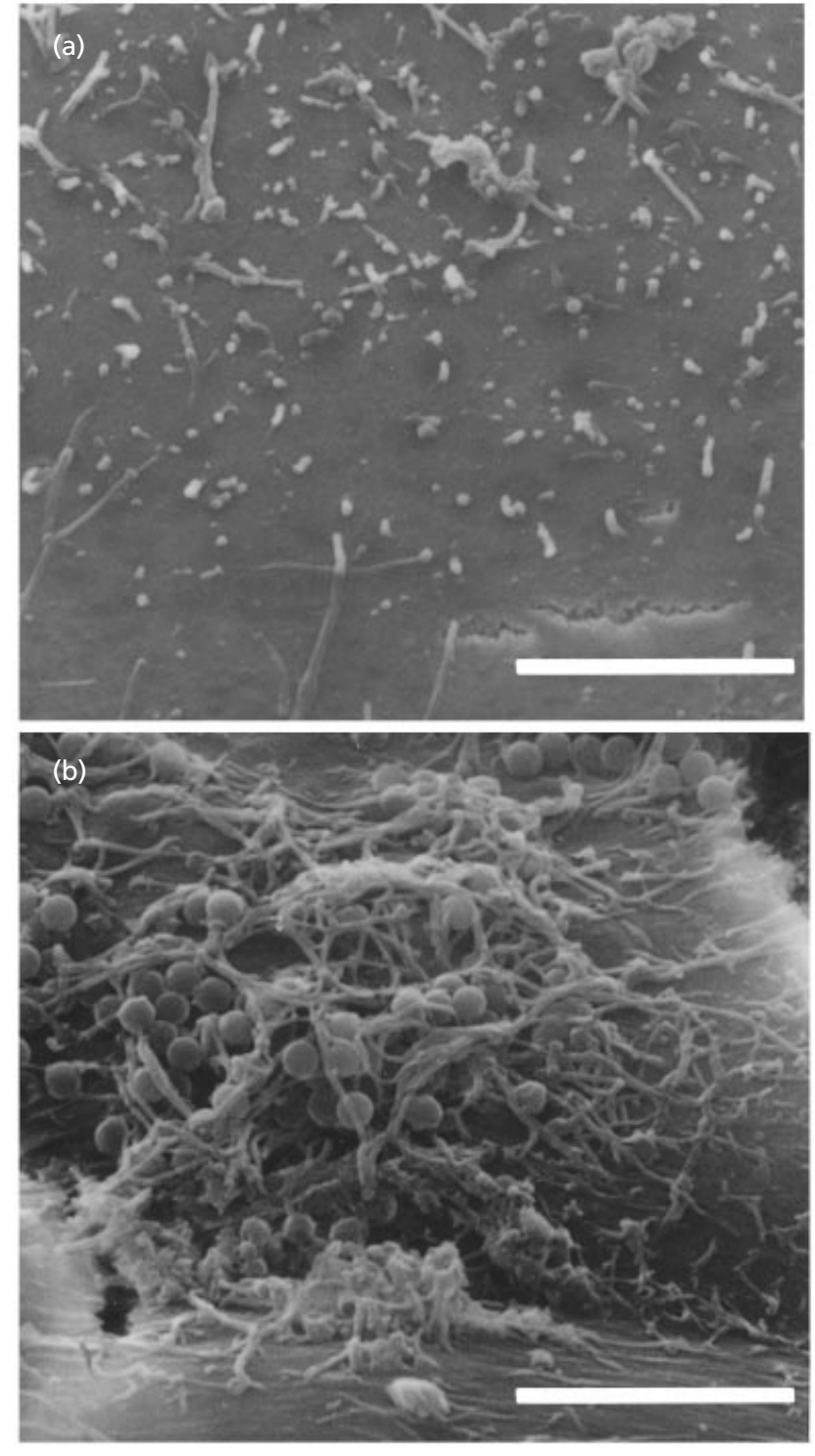

Fig. 4. Scanning electron micrographs of HEp-2 cells showing lack of binding of beads coated with MBP-Int280CS (a), in comparison to binding of beads coated with MBP-Int280 along with MLP elongation (b). Bars, $5 \mu \mathrm{m}$.

association with adhering Covaspheres, in a binding pattern which resembled that of UMD864 (Fig. 4).

\section{EPEC interaction with Caco-2 cells}

Caco-2 cells possess microvilli on their apical membrane, although these are less developed than in paediatric small intestine obtained on mucosal biopsy. After $3 \mathrm{~h}$ incubation, A/E lesions were apparent at sites of E2348/69 attachment and microvilli were reduced in number on the cell surface compared to uninoculated samples (Fig. 5a, b). CVD206 adhesion was also associated with a reduction in the number of microvilli on the cell surface, although $\mathrm{A} / \mathrm{E}$ lesions were not 

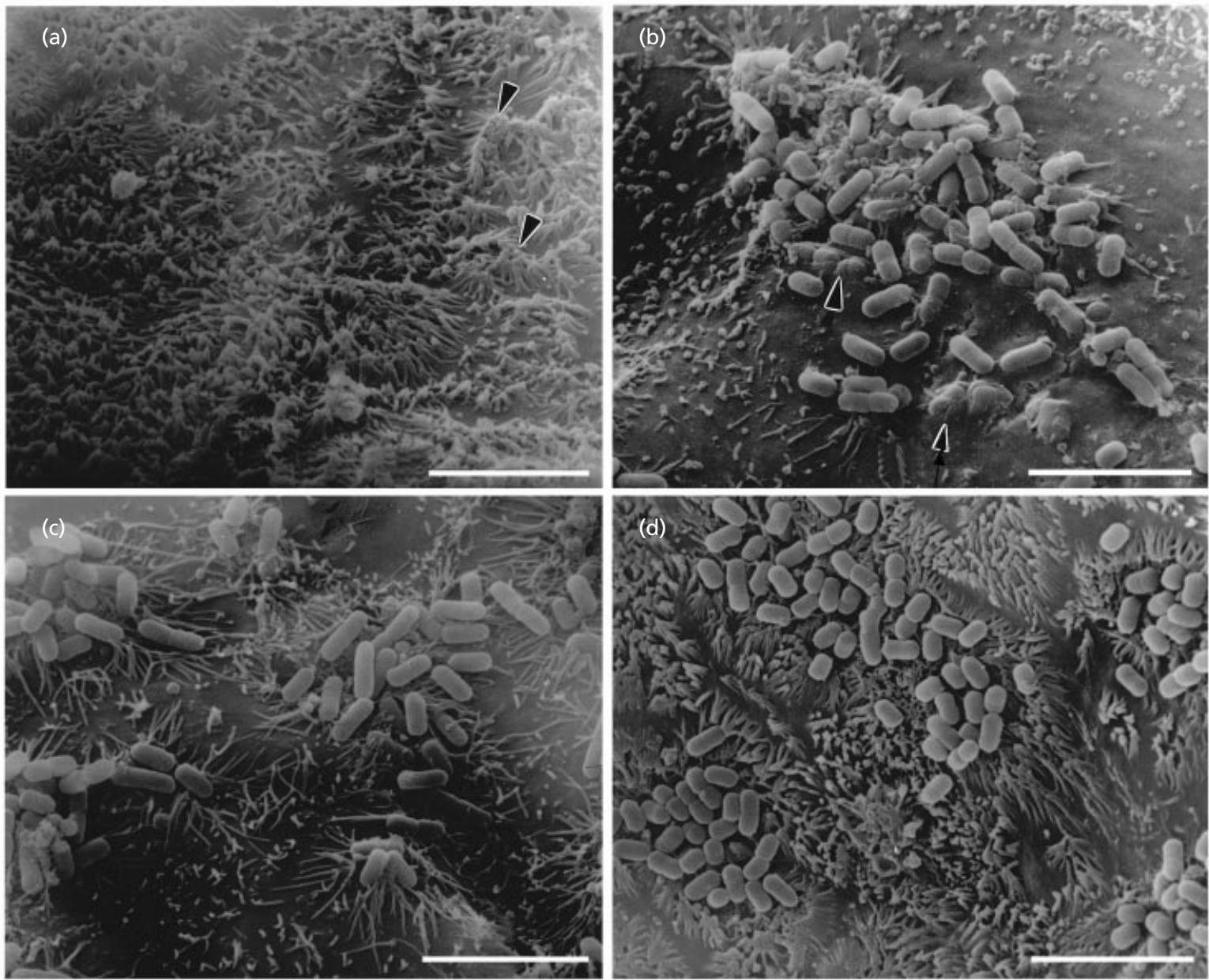

Fig. 5. Scanning electron micrographs showing the interaction of Caco-2 cells with bacterial strains. (a) Microvilli are present on the cell surface in uninoculated samples; microvillus tips tend to clump together (arrow). (b) E2348/69 shows $\mathrm{A} / \mathrm{E}$ lesion formation (arrows) and reduction in microvillus number. (c) CVD206 shows a similar reduction in microvillus number but no evidence of A/E lesions at sites of bacterial attachment. (d) UMD864 adhere to the cell surface but there is no evidence of changes in microvillus appearance. Bars, $5 \mu \mathrm{m}$.

evident (Fig. 5c). In contrast to incubations with HEp-2 cells, adherence of UMD864 to the cell surface was not associated with microvillus elongation and the microvilli appeared similar to uninoculated samples (Fig. 5d).

\section{Infection of human intestine in IVOC produces localized microvillus elongation and degeneration}

B171 and E2348/69 showed localized colonization of the human explants. These colonies demonstrated elongation of microvilli at their edges with microvillus breakdown towards the centre where bacterial adhesion was obvious (Fig. 6). Immediately neighbouring cells without adhering bacteria appeared normal. There was no evidence of adhesion of either CVD206 or UMD864 to paediatric intestinal IVOC, and the samples appeared similar to the uninoculated control (data not shown); in each case the positive control showed localized adhesion in a similar manner to Fig. 6. Co-incubation, where it might be expected that CVD206 would 'activate' the mucosa and permit UMD864 to adhere (Rosenshine et al., 1996), also showed no evidence of bacterial adhesion.

\section{DISCUSSION}

This paper concerns the biological activity of intimin in three different in vitro model systems, HEp-2 cell culture, Caco- 2 cell culture and paediatric small intestinal mucosa in organ culture. Two wild-type EPEC strains were capable of causing $\mathrm{A} / \mathrm{E}$ lesions in all systems, but the interaction of mutant strains varied in the systems used.

In the present investigation we have shown that HEp-2 cells respond to EPEC infection by producing and elongating MLP, which enmesh and appear to anchor the bacteria to the cell surface. In agreement with previous reports (Yamamoto et al., 1992; Silva et al., 1989) we observed that MLP increase in number during initial stages of infection, and then elongate and mobilize around adhering and replicating bacteria. However, by 

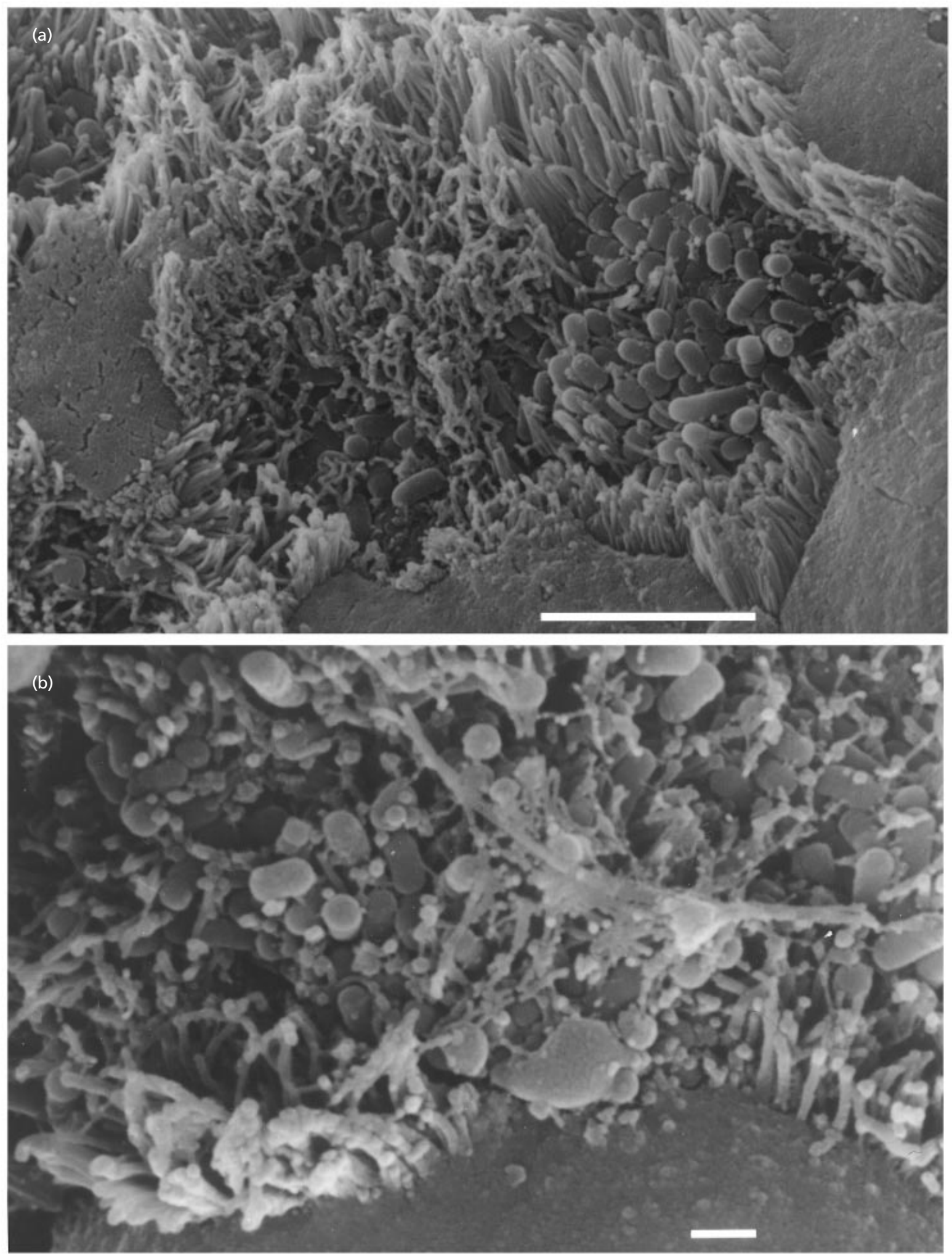

Fig. 6. Paediatric IVOC: scanning electron micrographs of localized colonies of (a) B171 on ileum and (b) E2348/69 on duodenum. Note elongated microvilli at periphery and shortened microvilli with debris centrally. Bars: $5 \mu \mathrm{m}$ (a); $1 \mu \mathrm{m}$ (b). 
140-180 min post-infection (once a typical bacterial cluster is formed and intimate contact is established), the cell surface neighbouring the LA cluster appears 'normal', without long MLP, as if they have decreased in numbers and returned to their pre-infected level. The presence of debris implies they degenerate rather than retract.

We demonstrate that, in agreement with previous observations (Knutton et al., 1987b; Hicks et al., 1998), microvillus elongation and degeneration is observed on EPEC infection of human intestine in IVOC. This suggests that the phenomena we observed on HEp-2 cells may be important in early events of intestinal colonization by EPEC. The bacterial strains CVD206 (intimin-minus) (Knutton et al., 1987b, and this paper) and UMD864 (EspB-minus) did not adhere to human IVOC, so we are unable to evaluate their effect on the human intestinal brush border. However, the effects of various EPEC mutants could be evaluated on HEp-2 cells.

We also tested the effect of EPEC E2348/69 and various derived mutants on Caco-2 cells. In contrast to human intestine in IVOC and to HEp-2 cells, there was no evidence of microvillus elongation, either with E2348/69 or with UMD864, although a decrease in microvillus number was observed with CVD206 in a similar manner to E2348/69.

Using defined EPEC mutants which were defective in the production of specific virulence factors required for $\mathrm{A} / \mathrm{E}$ lesion formation, it was possible to determine the function of these factors during MLP elongation on HEp-2 cells. CVD206, a strain unable to form intimate interactions with host cell membranes due to a deletion mutation in the eae gene, did not induce MLP elongation. In contrast, UMD864 and UMD872, EPEC derivatives deficient in Esp-dependent activation of host cell signal transduction pathways, induced 'cage-like' structures of MLP origin at the site of bacterial adherence. Since UMD864 and UMD872 still express intimin at wild-type levels, they can be considered for practical considerations as intimin-coated particles. Indeed, Int280-coated beads not only induced MLP elongation, but were associated with the MLP in 'cagelike' structures.

An important aspect of this study is the fact that MLP production is induced by intimin (both intimin $\alpha$ from strain E2348/69 and intimin $\beta$ from strain B171), even in the absence of Esp-mediated cell signalling and translocation of Tir. This result supports observations that Int 280 can, on its own, bind to HEp- 2 cells (Hartland et al., 1999; Frankel et al., 1995, 1996b), and suggests that intimin can bind to both Tir and to a receptor encoded by the host cell. Our results indicate intimin, by activation of host cell signalling, is the bacterial virulence factor responsible for the alterations in the MLP population during early stages of EPEC interaction with HEp-2 cells, whilst translocation of Tir and/or EspB, possibly in concert with other proteins, induces degeneration of MLP so that they return to pre-infected size and numbers. However, the nature of the signals involved in the MLP production and reduction is at present not known. It is worth noting that when the cell monolayers were infected with wild-type EPEC for $6 \mathrm{~h}$, the adhering bacterial clusters grew to the extent of covering the entire cell surface. In contrast, at $6 \mathrm{~h}$ postinoculation, only a few CVD206 and UMD864 bacteria remained associated with the HEp-2 cell monolayers. These results suggest that the ability to form A/E lesions and to intimately attach to the host cell enhances longterm bacteria-host cell interactions, which is consistent with our recent finding that intimate attachment is required for binding of EPEC to human intestinal cells in IVOC (Hicks et al., 1998).

Following infection of HEp-2 cells with JPN15 (pCVD450) extensive 'cage-like' structures, similar to those induced during infection with UMD864, were observed 1 and $2 \mathrm{~h}$ post-infection, although only a few bacteria were seen adhering to the cell surface. In contrast, by $6 \mathrm{~h}$ post-infection larger numbers of bacteria forming $\mathrm{A} / \mathrm{E}$ lesions were observed and no MLP were seen. The pattern of adhesion appeared diffuse and may reflect the absence of Bfp-related three-dimensional colony formation as seen with E2348/69 (Hicks et al., 1998). The results indicate that two sequential signal transduction pathways are activated during EPEC infection : intimin-mediated production of MLP, and MLP degeneration and $\mathrm{A} / \mathrm{E}$ lesion formation.

Evidence is accumulating that intimin binds to more than one receptor (Hartland et al., 1999). Previously, we have shown that MBP-Int280 binds immobilized $\beta 1$ integrins and can mediate integrin-dependent human CD4 $+\mathrm{T}$ cell adherence to MBP-Int280-coated wells (Frankel et al., 1996a). Wolff et al. (1998) have shown that EspB is also translocated into HeLa cells and that intimin is needed for full translocation efficiency, whilst Kenny et al. (1997) have shown that translocation of Tir is dependent on expression of EspB. The resemblance of the third domain of Int280 to C-type lectins (Kelly et al., 1999), alternatively indicates that intimin may bind to a carbohydrate moiety. We have also reported that both Int 280 and Int $280 \mathrm{C} / \mathrm{S}$ or Int $280 \mathrm{C} / \mathrm{A}$ (biologically inactive forms of Int 280 in which Cys 937 has been substituted with Ser or Ala, respectively) bind Tir and that Int280, but not Int $280 \mathrm{C} / \mathrm{S}$, binds to cells in the absence of Tir (Hartland et al., 1999). Together, these data provide strong evidence that intimin might have two binding activities, i.e. to Tir and to a host-cell receptor; these two binding activities may induce different signalling pathways. The identity of the hostcell intimin receptor is not yet known. Experiments testing the above hypotheses are under way.

\section{ACKNOWLEDGEMENTS}

We wish to thank Dr Jim Kaper and Dr Michael Donnenberg, University of Maryland, USA, for providing the E2348/69 derivatives. This work was supported by grants from the Wellcome Trust, UK (G.D.), the BBSRC, UK (A.D.P. and G.F.) and Conacyt, Mexico (J.A.G.). 
Alan D. Phillips and Jorgé Giròn contributed equally to this work.

\section{REFERENCES}

Adu-Bobie, J., Frankel, G., Bain, C., Goncalves, A. G., Trabulsi, L. R., Douce, G., Knutton, S. \& Dougan, G. (1998). Detection of intimins $\alpha, \beta, \gamma$, and $\delta$, four intimin derivatives expressed by attaching and effacing microbial pathogens. J Clin Microbiol 36, 662-668.

Bain, C., Keller, R., Collington, G. K., Trabulsi, L. R. \& Knutton, S. (1998). Increased levels of intracellular calcium are not required for the formation of attaching effacing lesions by enteropathogenic or enterohemorrhagic Escherichia coli. Infect Immun 66, 3900-3908.

Baldini, M. M., Kaper, J. B., Levine, M. M., Candy, D. C. A. \& Moon, H. W. (1983). Plasmid-mediated adhesion in enteropathogenic Escherichia coli. J Pediatr Gastroenterol Nutr 2, 534-538.

Ben-Ami, G., Ozeri., V., Hanski, E., Hofmann, F., Aktories, K., Hahn, K. M., Bokoch, G. M. \& Rosenshine, I. (1998). Agents that inhibit Rho, Rac, and Cdc42 do not block formation of actin pedestals in HeLa cells infected with enteropathogenic Escherichia coli. Infect Immun 66, 1755-1758.

Cravioto, A., Gross, R. J., Scotland, S. M. \& Rowe, B. (1979). An adhesive factor found in strains of Escherichia coli belonging to the traditional infantile enteropathogenic serotypes. Curr Microbiol 3, 95-99.

Donnenberg, M. S. \& Kaper, J. B. (1991). Construction of an eae deletion mutant of enteropathogenic Escherichia coli by using a positive selection suicide vector. Infect Immun 59, 4310-4317.

Donnenberg, M. S., Yu, J. \& Kaper, J. B. (1993). A second chromosomal gene necessary for intimate attachment of enteropathogenic Escherichia coli to epithelial cells. J Bacteriol 175, $4670-4680$.

Frankel, G., Candy, D. C. A., Everest, P. \& Dougan, G. (1994). Characterization of the C-terminal domains of intimin-like proteins of enteropathogenic and enterohemorrhagic Escherichia coli, Citrobacter freundii, and Hafnia alvei. Infect Immun 62, 1834-1842.

Frankel, G., Candy, D. C. A., Fabiani, E., Adu-Bobie, J., Gil, S., Novakova, M., Phillips, A. D. \& Dougan, G. (1995). Molecular characterization of a carboxy-terminal eukaryotic-cell-binding domain of intimin from enteropathogenic Escherichia coli. Infect Immun 63, 4323-4328.

Frankel, G., Lider, O., Hershkoviz, R., Mould, A. P., Kachalsky, S. G., Candy, D. C. A., Cahalon, L., Humphries, M. J. \& Dougan, G. (1996a). The cell-binding domain of intimin from enteropathogenic Escherichia coli binds to $\beta 1$ integrins. J Biol Chem 271, 20359-20364.

Frankel, G., Phillips, A. D., Hicks, S. \& Dougan, G. (1996b). Enteropathogenic Escherichia coli-mucosal infection models. Trans R Soc Trop Med Hyg 90, 347-352.

Frankel, G., Phillips, A. D., Rosenshine, I., Dougan, G., Kaper, J. B. \& Knutton, S. (1998). Enteropathogenic and enterohemorrhagic Escherichia coli: more subversive elements. Mol Microbiol 30, 911-921.

Giron, J. A., Ho, A. S. \& Schoolnik, G. K. (1991). An inducible bundle-forming pilus of enteropathogenic Escherichia coli. Science 254, 710-713.

Gomez-Duarte, O. G. \& Kaper, J. B. (1995). A plasmid-encoded regulatory region activates chromosomal eaeA expression in enteropathogenic Escherichia coli. Infect Immun 63, 1767-1776.
Hartland, E. L., Batchelor, M., Delahay, R. M., Hale, C., Matthew, S., Dougan, G., Knutton, S., Connerton, I. \& Frankel, G. (1999). Binding of intimin from enteropathogenic Escherichia coli to Tir and to host cells. Mol Microbiol 32, 151-158.

Hicks, S., Frankel, G., Kaper, J. B., Dougan, G. \& Phillips, A. D. (1998). Role of intimin and bundle-forming pili in enteropathogenic Escherichia coli adhesion to pediatric intestinal tissue in vitro. Infect Immun 66, 1570-1578.

Jarvis, K. J., Giron, J. A., Jerse, A. E., McDaniel, T. K., Donnenberg, M. S. \& Kaper, J. B. (1995). Enteropathogenic Escherichia coli contains a putative type III secretion system necessary for the export of proteins involved in attaching and effacing lesion formation. Proc Natl Acad Sci USA 92, 7996-8000.

Jerse, A. E., Yu, J., Tall, B. D. \& Kaper, J. B. (1990). A genetic locus of enteropathogenic Escherichia coli necessary for the production of attaching effacing lesions on tissue culture cells. Proc Natl Acad Sci USA 87, 2842-2844.

Kalman, D., Weiner, O. D., Goosney, D. L., Sedat, J. W., Finlay, B. B., Abo, A. \& Bishop, J. M. (1999). Enteropathogenic E. coli acts through WASP and Arp2/3 complex to form actin pedestals. Nature Cell Biol 1, 389-391.

Kelly, G. S., Prasannan, S., Daniell, S., Flemming, K., Frankel, G., Dougan, G., Connerton, I. \& Matthew, S. (1999). Structure of the cell-adhesion fragment of intimin from enteropathogenic Escherichia coli. Nature Struct Biol 6, 313-318.

Kenny, B. \& Finlay, B. B. (1995). Protein secretion by enteropathogenic Escherichia coli is essential for transducing signals to epithelial cells. Proc Natl Acad Sci USA 92, 7991-7995.

Kenny, B. \& Finlay, B. B. (1997). Intimin-dependent binding of enteropathogenic Escherichia coli to host cells triggers novel signaling events, including tyrosine phosphorylation of phospholipase C- $\gamma 1$. Infect Immun 65, 2528-2536.

Kenny, B., Lai, L., Finlay, B. B. \& Donnenberg, M. S. (1996). EspA, a protein secreted by enteropathogenic Escherichia coli, is required to induce signals in epithelial cells. Mol Microbiol 20, 313-323.

Kenny, B., DeVinney, R., Stein, M., Reinscheid, D. J., Frey, E. \& Finlay, B. B. (1997). Enteropathogenic E. coli (EPEC) transfers its receptor for intimate adherence into mammalian cells. Cell 91, 511-520.

Knutton, S., Baldini, M. M., Kaper, J. B. \& McNeish, A. S. (1987a). Role of plasmid-encoded adherence factors in adhesion of enteropathogenic Escherichia coli to HEp-2 cells. Infect Immun 55, 78-85.

Knutton, S., Lloyd, D. R. \& McNeish, A. S. (1987b). Adhesion of enteropathogenic Escherichia coli to human intestinal enterocytes and cultured human intestinal mucosa. Infect Immun 55, 69-77.

Knutton, S., Baldwin, T., Williams, P. H. \& McNeish, A. S. (1989). Actin accumulation at sites of bacterial adhesion to tissue culture cells: basis of a new diagnostic test for enteropathogenic and enterohemorrhagic Escherichia coli. Infect Immun 57, 1290-1298.

Knutton, S., Adu-Bobie, J., Bain, C., Phillips, A. D., Dougan, G. \& Frankel, G. (1997). Down regulation of intimin expression during attaching and effacing enteropathogenic Escherichia coli adhesion. Infect Immun 65, 1644-1652.

Knutton, S., Rosenshine, I., Pallen, M. J., Nisan, I., Neves, B. C., Bain, C., Wolff, C., Dougan, G. \& Frankel, G. (1998). A novel EspA associated surface organelle of enteropathogenic Escherichia coli involved in protein translocation into epithelial cells. EMBO J 17, 2166-2176.

Lai, L., Wainwright, L. A., Stone, K. D. \& Donnenberg, M. S. (1997). A third secreted protein that is encoded by the entero- 
pathogenic Escherichia coli pathogenicity island is required for transduction of signals and for attaching and effacing activities in host cells. Infect Immun 65, 2211-2217.

Levine, M. M., Berquist, E. J., Nalin, D. R., Waterman, D. H., Hornick, R. B., Young, C. R., Scotman, S. \& Rowe, B. (1978). Escherichia coli strains that cause diarrhoea but do not produce heat-labile or heat-stable enterotoxins and are non-invasive. Lancet i, 1119-1122.

McDaniel, T. K., Jarvis, K. G., Donnenberg, M. S. \& Kaper, J. B. (1995). A genetic locus of enterocyte effacement conserved among diverse enterobacterial pathogens. Proc Natl Acad Sci USA 92, 1664-1668.

Manjarrez-Hernandez, H. A., Baldwin, T. J., Williams, P. H., Haigh, R., Knutton, S. \& Aitken, A. (1996). Phosphorylation of myosin light chain at distinct sites and its association with the cytoskeleton during enteropathogenic Escherichia coli infection. Infect Immun 64, 2368-2370.

Moon, H. W., Whipp, S. C., Argenzio, R. A., Levine, U. M. \& Giannella, R. (1983). Attaching and effacing activities of rabbit and human enteropathogenic Escherichia coli in pig and rabbit intestines. Infect Immun 41, 1340-1351.

Nataro, J. P. \& Kaper, J. B. (1998). Diarrheagenic Escherichia coli. Clin Microbiol Rev 11, 141-201.

Rosenshine, I. \& Finlay, B. B. (1993). Exploitation of host signal transduction pathways and cytoskeletal functions by invasive bacteria. Bioassays 15, 17-24.

Rosenshine, I., Donnenberg, M. S., Kaper, J. B. \& Finlay, B. B. (1992). Signal transduction between enteropathogenic Escherichia coli (EPEC) and epithelial cells: EPEC induces tyrosine phosphorylation of host cell proteins to initiate cytoskeletal rearrangement and bacterial uptake. EMBO J 11, 3551-3560.

Rosenshine, I., Ruschkowski, S. \& Finlay, B. B. (1996). Expression of attaching/effacing activity by enteropathogenic Escherichia coli depends on growth phase, temperature, and protein synthesis upon contact with epithelial cells. Infect Immun 64, 966-973.

Rothbaum, R. J., Partin, J. C., Saalfield, K. \& McAdams, A. J. (1983). An ultrastructural study of enteropathogenic Escherichia coli infection in human infants. Ultrastruct Pathol 4, 291-304.

Scaletsky, I. C. A., Silva, M. L. M. \& Trabulsi, L. R. (1984). Distinctive patterns of adherence of enteropathogenic Escherichia coli to HeLa cells. Infect Immun 45, 534-536.

Silva, M. L. M., Mortara, R. A., Barros, H. C., de Souza, W. \& Trabulsi, L. R. (1989). Aggregation of membrane-associated actin filaments following localised adherence of enteropathogenic Escherichia coli. J Cell Sci 93, 439-446.

Ulshen, M. H. \& Rollo, J. L. (1980). Pathogenesis of Escherichia coli gastroenteritis in man - another mechanism. N Engl J Med 302, 99-101.

Wolff, C., Nisan, I., Hanski, E., Frankel, G. \& Rosenshine, I. (1998). Protein translocation into epithelial cells by infecting enteropathogenic Escherichia coli. Mol Microbiol 28, 143-155.

Yamamoto, T., Koyama, Y., Matsumoto, M. \& 7 other authors (1992). Localized, aggregative and diffuse adherence to HeLa cells, plastic, and human small intestines by Escherichia coli isolated from patients with diarrhea. J Infect Dis 166, 1295-1310.

Received 20 December 1999; revised 21 March 2000; accepted 24 March 2000. 